\title{
Accelerated Death of Aerobacter aerogenes Starved in the Presence of Growth-Limiting Substrates
}

\author{
By J. R. POSTGATE* AND J. R. HUNTER \\ Microbiological Research Establishment, Porton Down, \\ Wiltshire, England
}

(Received 28 August 1963)

\begin{abstract}
SUMMARY
Substrate-accelerated death (Postgate \& Hunter, 1963 $a$ ) was observed with glycerol-, glucose-, ribose-, ammonium- or phosphate-limited populations of Aerobacter aerogenes grown in defined media and starved in nonnutrient buffer; sulphate- or magnesium-limited organisms did not show this. Glucose or pyruvate accelerated death of starved populations obtained from a complex medium. Lactate-accelerated death of Escherichia coli and glucose-accelerated death of Serratia marcescens were also observed with populations of appropriate nutritional status. Glycerol-accelerated death of glycerol-limited $A$. aerogenes occurred with organisms from batch or continuous cultures grown at various $\mathrm{pH}$ values; it showed a population effect and was particularly pronounced in $0.15 \mathrm{M}-\mathrm{NaCl}$ buffered with phosphate. Continued presence of glycerol was necessary and the glycerol was metabolized. Survivors showed prolonged division lags. Tricarboxylic acid cycle intermediates, but not glucose or ribose, also accelerated death. Glycerol-accelerated death was not delayed by malonate, fluoride or fluoracetate; iodo-acetate delayed its onset but did not affect its rate; 'uncoupling' agents antagonized it though they were themselves toxic. Glycerol-accelerated death was not accompanied by accelerated breakdown of the osmotic barrier, nor by leakage of materials associated with cold shock nor by acquiring sensitivity to cold shock. No catabolism of DNA or protein accompanied it; polysaccharide was synthesized; no change in the rate of degradation of RNA was observed. Coloured substances, pyridine nucleotides, white-fluorescent material and material which absorbed at $220-230 \mathrm{~m} \mu$ were released during glycerol-accelerated death. Magnesium ions prevented glycerol-accelerated death.
\end{abstract}

\section{INTRODUCTION}

Postgate \& Hunter (1963a) showed that substrates which had limited the growth of populations of certain Gram-negative bacteria could accelerate their death when they were subsequently starved in non-nutrient buffer. The phenomenon was termed 'substrate-accelerated death' and was shown with nitrogen-, phosphateand carbon-limited bacterial populations. Sulphate-limited populations differed in that the carbon source, not sulphate, accelerated death. Magnesium-limited populations did not show substrate-accelerated death. The present paper describes substrate-accelerated death in fuller detail and presents data which exclude certain possible interpretations of glycerol-accelerated death of glycerol-limited Aerobacter aerogenes.

\footnotetext{
* Present address : Royal Veterinary College, Royal College Street, London, N.W.1., England.
} 


\section{ME'THODS}

Organisms and culture. The variant strain of Aerobacter aerogenes NCTC 418, described by Postgate \& Hunter (1962), was maintained in the same continuous culture apparatus and was in its third and fourth year of growth at a dilution rate of $0 \cdot 25 \mathrm{hr}^{-1}$, temperature $40^{\circ}$ and $\mathrm{pH}$ value $7 \cdot 0 \pm 0 \cdot 1$. Growth was limited to a yield equivalent to $1-1 \cdot 1 \mathrm{mg}$. dry wt. organism $/ \mathrm{ml}$. (about $2 \cdot 3 \times 10^{9}$ bacteria $/ \mathrm{ml}$.) by the glycerol concentration ( $2 \mathrm{~g}$./1.) in the defined medium previously described. (Yields of organism and population densities will be expressed in ' $\mathrm{mg} . / \mathrm{ml}$.', implying ' equiv. dry wt. bacteria/ml.'.) For growth in other nutritional conditions a second chemostat was inoculated from the first 'master' culture and with the modified media and conditions described by Postgate \& Hunter (1962; in that publication the sulphate-limiting medium was incorrectly described [see addendum p. 473). For glucose or ribose limitation the regular medium was used with $2 \mathrm{~g}$./l. of these compounds in place of glycerol; the yields were: 0.95-1 $\mathrm{mg} . / \mathrm{ml}$. from glucose, and $0 \cdot 85-0.9 \mathrm{mg} . / \mathrm{ml}$. from ribose. In a few experiments organisms other than A. aerogenes NCTC 418 were used.

Viability was determined by slide culture (Postgate, Crumpton \& Hunter, 1961), except where mentioned, on the glycerol medium supplemented with casein hydrolysate, yeast extract and Douglas's meat digest broth (Medical Research Council, 1931); with glucose- or ribose-limited organisms the appropriate compound replaced glycerol. Incubation periods of $4-5 \frac{1}{2} \mathrm{hr}$ were used for slide culture of populations dying in the presence of substrate because the survivors of substrate-accelerated death showed long division lags (see below).

Starvation. For reasons given in the text two main procedures for starving organisms were used during this work. The 'saline tris procedure' was that described by Postgate \& Hunter (1962): the organisms were washed twice in saline, suspended in distilled water and diluted to $20 \mu \mathrm{g} . / \mathrm{ml}$. for starvation at $40^{\circ}$ in aerated $0.15 \mathrm{M}$ $\mathrm{NaCl}$ buffered to $\mathrm{pH} \mathbf{7 \cdot 0} \pm \mathbf{0 \cdot 1}$ with tris and containing a trace of ethylenediaminetetra-acetate. The 'saline phosphate procedure' avoided exposure to distilled water: organisms were washed only once and the saline was buffered to $\mathrm{pH} 6 \cdot 3$ (optimal for survival of the strain) or to $\mathrm{pH} 7 \cdot 3$ with $10 \%(\mathrm{v} / \mathrm{v})$ of $\mathrm{M} / \mathbf{1 5}$-sodium potassium phosphate buffer.

Optical and analytical procedures. These were mostly described previously (Postgate \& Hunter, 1962). Glycerol was estimated by oxidation with periodate followed by colorimetric determination of formaldehyde with chromotropic acid (Neish, 1950). Magnesium was determined by the Titan Yellow procedure of Garner (1946), scaled down 10-fold and omitting treatment with trichloroacetic acid. Whole bacteria were wet-ashed by repeated evaporation with $\mathrm{HNO}_{3}$ in the presence of $\mathrm{H}_{2} \mathrm{SO}_{4}$ before analysis for $\mathrm{Mg}$.

\section{RESULTS}

\section{Circumstances in which substrate-accelerated death occurred}

Aerobacter aerogenes. When organisms were harvested from continuous culture in the glycerol medium with glycerol limiting growth, and were then starved in saline tris buffer, they showed accelerated death with $10 \mathrm{~mm}-$ glycerol; the $\mathrm{pH}$ value remained unchanged throughout. Other major components of the growth medium 
(sulphate, phosphate, potassium, ammonium) had no influence on the death rate but certain trace elements $\left(\mathrm{Mg}^{2+}, \mathrm{Ca}^{2+}\right.$; and to some extent $\left.\mathrm{Fe}^{3+}\right)$ were protective (Postgate \& Hunter, 1962). Further experiments, with the saline tris procedure, showed that glucose $(10 \mathrm{~mm})$ or ribose $(10 \mathrm{~mm})$ did not accelerate death, though dyereduction tests indicated that both these substrates were metabolized by the organisms (Table 1). A continuous culture limited by ribose was therefore set up. The population did not show significant ribose-accelerated death when subjected to

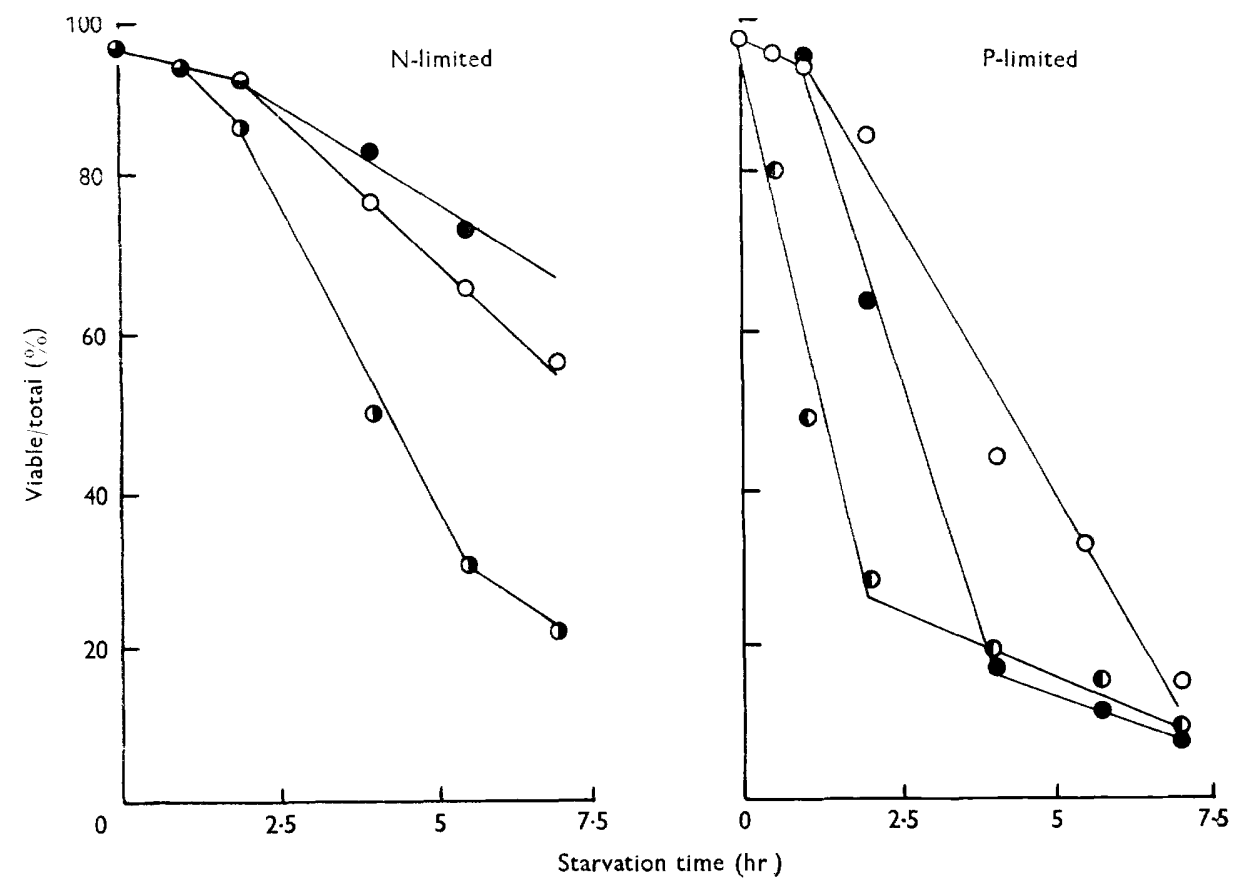

Fig. 1. Substrate-accelerated death of nitrogen- and phosphate-limited Aerobacter aerogenes. Organisms harvested from continuous culture, washed and starved at about $20 \mu \mathrm{g} . / \mathrm{ml}$. in aerated saline tris buffer $(\mathrm{pH} 7 \cdot 0)$ at $40^{\circ}$. Viabilities were determined by

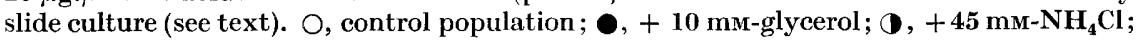
D, $+10 \mathrm{~mm}-\mathrm{KH}_{2} \mathrm{PO}_{4}$.

Table 1. Reduction of methylene blue by glycerol-limited Aerobacter aerogenes

Aerobacter aerogenes organisms from continuous culture were aerated for $15 \mathrm{~min}$. at $40^{\circ}$ to remove residual glycerol and $2 \mathrm{ml}$. portions (equiv. $2 \mathrm{mg}$. dry wt. organisms) added to $4 \mathrm{ml}$. portions of saline tris buffer ( $\mathrm{pH} 7 \cdot 0$ ), containing $10 \mathrm{~mm}$ substrates, in Thunberg tubes. After evacuation and equilibration for $6 \mathrm{~min}$. at $40^{\circ}, 0.5 \mathrm{ml}$. methylene blue was added (final concn. $0.67 \mathrm{~mm}$ ) and the decolorization times noted. Means of duplicates are quoted.

Substrate

Glycerol

Glucose

Ribose

None
Decolorization time (min.)

$1 \cdot 16$

$1 \cdot 83$

$4 \cdot 85$

30 
the saline tris procedure but a pronounced effect occurred with the saline phosphate procedure (e.g. $8.7 \%$ died $/ \mathrm{hr}$ in saline phosphate $(\mathrm{pH} 7 \cdot 3) ; 83 \%$ were dead in $0.5 \mathrm{hr}$ with buffer $+10 \mathrm{~mm}$-ribose). Glycerol also accelerated death $(93 \%$ dead in $0.5 \mathrm{hr}$ with $10 \mathrm{~mm}$ glycerol). A glucose-limited continuous culture gave a population that showed slight glucose-accelerated death with the saline tris procedure but a pronounced effect with saline phosphate (death rate: $17 \% / \mathrm{hr}$ at $\mathrm{pH} 7 \cdot 3 ; 94 \% / \mathrm{hr}$ with $10 \mathrm{~mm}$-glucose). Continuous cultures in which nutrients other than the carbon-cumenergy source limited growth were set up to observe whether glycerol or the limiting

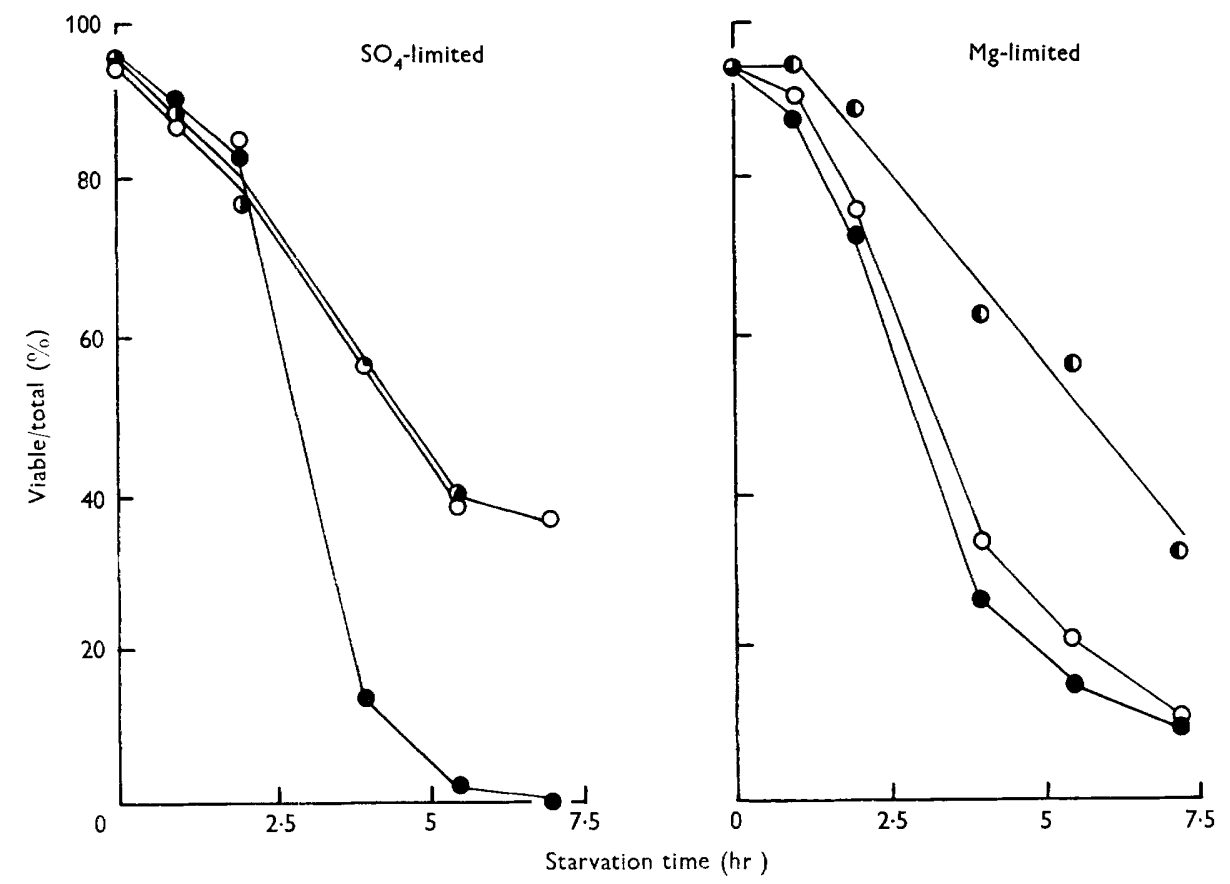

Fig. 2. Effect of substrates on death of sulphate- and magnesium-limited Aerobacter aerogenes. Organisms tested as for Fig. 1. $\bigcirc$, control population; $\odot,+10 \mathrm{~mm}$-glycerol;

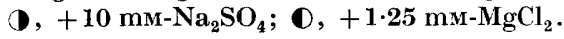

nutrient accelerated death. With the saline tris procedure $\mathrm{N}$-limited organisms showed $\mathrm{NH}_{4}$-accelerated death, but glycerol delayed death; P-limited organisms showed $\mathrm{PO}_{4}$-accelerated death and glycerol also accelerated death, though to a lesser extent (Fig. 1). S-limited organisms did not show accelerated death with sulphate but glycerol was active (Fig. 2). Mg-limited organisms showed delayed death with $\mathrm{MgCl}_{2}$ and sometimes with glycerol (Fig. 2). A population of Aerobacter aerogenes NCTC 418 was grown in Douglas's meat digest broth and we confirmed the observation of Strange, Dark \& Ness (1961) that glucose (10 mm) accelerated its death in saline phosphate at $\mathrm{pH} 6 \cdot 5$. Sodium pyruvate $(10 \mathrm{~mm})$ was also active (Fig. 3); data illustrating the acceleration of death of mannitol-limited stationary phase $A$. aerogenes by mannitol or glucose were quoted by Postgate \& Hunter (1963a). 
Other bacteria. Fig. 4 illustrates accelerated death of lactate-limited Escherichia coli (Jepp) by lactate or pyruvate, and of glucose-limited Serratia marcescens (м 148) by glucose, both from batch cultures. In general, substrate-accelerated death was less pronounced with stationary phase cultures, and the appearance of the slide cultures of the dying populations suggested to us that cryptic growth (see Postgate \& Hunter, 1962) was masking the phenomenon. Cryptic growth was obvious as an increase in optical density of the suspension 'starved' with substrate in unsuccessful attempts to demonstrate substrate-accelerated death with mannitol-limited Bacillus subtilis, acetate-limited Pseudomonas ovalis and glucose-limited Candida utilis.

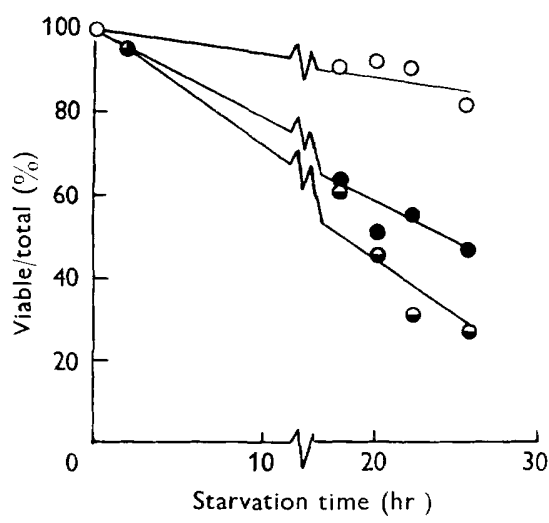

Fig. 3

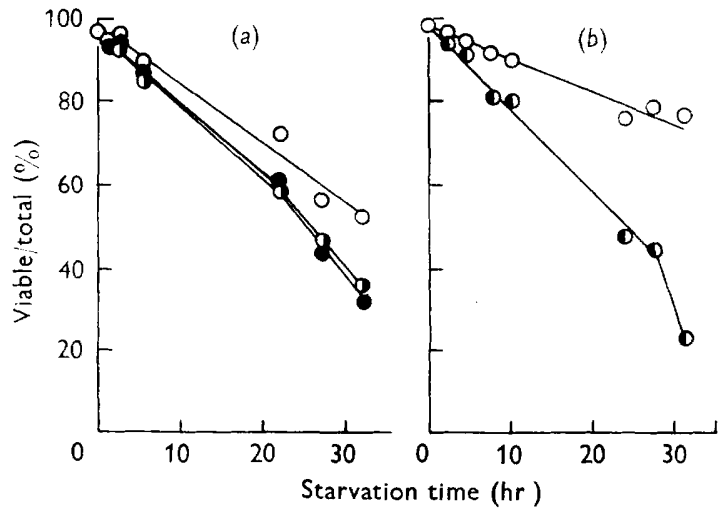

Fig. 4

Fig. 3. Effect of substrates on death of stationary phase Aerobacter aerogenes from a complex medium. Organisms grown at $37^{\circ}$ in Douglas's meat digest broth were washed twice and starved (at about $20 \mu \mathrm{g} . / \mathrm{ml}$.) in aerated saline phosphate buffer $\left(\mathrm{pH} \mathrm{6.5)}\right.$ at $37^{\circ}$. Viabilities by slide culture on Douglas's meat digest agar. $O$, control ; $\theta$, $+10 \mathrm{~mm}$-glucose; - +10 mM-sodium pyruvate.

Fig. 4. Substrate-accelerated death of Escherichia coli and Serratia marcescens. E. coli strain Jepp, and $S$. marcescens $\mathrm{M} 148$ were grown at $37^{\circ}$ in lactate + salts and glucose + salts defined media, respectively, in shaken flasks containing sufficient air to allow complete oxidation of all of the carbon substrate provided. When in the stationary phase, the organisms were washed and starved at about $20 \mu \mathrm{g} . / \mathrm{ml}$. in aerated saline phosphate buffer (pH 6.5) at $37^{\circ}$. Viabilities were determined by slide culture on the medium mentioned in the text with sodium lactate or glucose in place of glycerol as appropriate. (a) E. coli; (b) S. marcescens. O, control population; $\bigcirc$, 10 mm-sodium lactate;,+ $10 \mathrm{~mm}$-sodium pyruvate; $+10 \mathrm{~mm}$-glucose.

\section{Glycerol-accelerated death of Aerobacter aerogenes}

Effect of washing and storage procedure. Postgate \& Hunter (1962) found that a brief exposure to distilled water experienced during preparation for starvation by the saline tris procedure committed the organisms to a faster death rate than would otherwise have occurred. Omission of exposure to distilled water did not abolish glycerol-accelerated death in saline tris buffer. Postgate \& Hunter (1962) also reported that the growth $\mathrm{pH}$ value of $7 \cdot 0$ was inferior to $\mathrm{pH} 6-6.5$ for survival during starvation. Since tris does not buffer appreciably at $\mathrm{pH}$ values below about $7 \cdot 0$ saline phosphate was adopted for general use unless comparison with earlier work with saline tris was required. At comparable $\mathrm{pH}$ values, glycerol-accelerated death was more pronounced in saline phosphate buffer than in saline tris buffer: at $\mathrm{pH} \mathbf{7 \cdot 3}$, 
$70 \pm 10 \%$ of the populations were dead in $1 \mathrm{hr}$ in saline phosphate buffer $+10 \mathrm{mm-}$

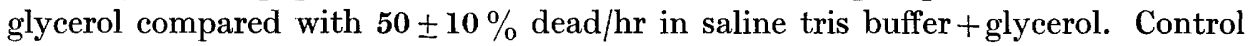
populations without glycerol died at $12-15 \% / \mathrm{hr}$ in either buffer.

Effect of washing procedure. Starvation by the saline phosphate procedure at $\mathrm{pH} \mathbf{7 \cdot 3}$ or $6 \cdot 3$ allowed pronounced glycerol-accelerated death, despite the absence of a pre-exposure to distilled water. When organisms were pre-exposed to distilled water, as for the saline tris procedure, their rates of glycerol-accelerated death were unchanged in saline phosphate buffers, though pre-exposure to water accelerated death in these buffers if glycerol were absent. Organisms washed exclusively in distilled water showed a small but reproducible decrease in their rate of glycerolaccelerated death compared with organisms washed in saline. Of a $97 \%$ viable population starved with $10 \mathrm{~mm}$-glycerol, $53 \%$ of those washed in distilled water were viable after 30 min. compared with $26 \%$ of those washed in saline; by $60 \mathrm{~min}$. both populations had fallen below $2 \%$ viable.

Growth characteristics of survivors. Casual observation suggested that survivors of death accelerated by ammonium, phosphate, glycerol etc. had long lag periods compared with survivors of starvation in plain buffer. The growth characteristics of survivors of glycerol-accelerated death were measured as follows. Populations in saline phosphate buffer ( $\mathrm{pH} 6 \cdot 4$ ) were starved for 0.5 or $1 \mathrm{hr}$ with and without glycerol, centrifuged, and re-suspended in liquid medium (that used for slide culture but without agar) warmed to $40^{\circ}$. At this point the viability of the population was determined by slide culture, its optical density (OD) measured, and the culture allowed to grow while aerated through a Pasteur pipette. Viabilities were measured during the lag phase and optical densities during growth. A semi-logarithmic plot of the OD increase was extrapolated to an OD equivalent to that of the viable proportion of the original inoculum (e.g. a population of initial OD of 0.03 and viability $66 \%$ was regarded as having a 'viable $O D$ ' of 0.02 ) and the intercept was taken as a measure of the lag. The lags observed were: $150 \mathrm{~min}$. for survivors of a population which had died to $66 \%$ viable during $30 \mathrm{~min} ., 240 \mathrm{~min}$. for one that had died to $10 \%$ viable over $1 \mathrm{hr}$. A control population starved without glycerol for $1 \mathrm{hr}$ decreased from 99 to $94 \%$ viable and had a lag period of $36 \mathrm{~min}$. No further death of survivors of glycerol-accelerated death during the lag phase was detected by slide culture, and populations derived from the survivors had mean generation times similar to that of the control population (51-54 min.). In these respects the survivors of substrate-accelerated death differed markedly from the survivors of freezing and thawing (Postgate \& Hunter, 1963c).

Comparison with plate counts. Slide culture can give false values for the viability if the scatter of individual lags is wide, due to overgrowth of dead organisms by colonies from individuals of short lag (Postgate et al. 1961). Though longer incubation times were adopted for the study of glycerol-accelerated death (see Methods), some comparisons with plate counts were made. Figure 5 illustrates that the agreement between slide and plate cultures was adequate; the increased lag of survivors of substrate-accelerated death was reflected in a longer incubation period required for the plates to reach a constant count.

Effect of recovery medium. The presence of glycerol in the recovery medium was not necessary for the expression of glycerol-accelerated death. The organism grew equally well on slide cultures on medium prepared according to the usual recipe but 
without glycerol. The survival curves of populations suffering glycerol-accelerated death were indistinguishable from those obtained with the glycerol medium. For these experiments the samples of the dying population were centrifuged and re-suspended in saline before slide cultivation to avoid carry-over of glycerol from the starvation buffer.

Effect of $p H$ value of growth. Continuous cultures of Aerobacter aerogenes were grown at $\mathrm{pH} 6 \cdot 5,5 \cdot 5$ and $4 \cdot 9$. Populations from these cultures all showed pronounced glycerol-accelerated death when tested at $\mathrm{pH} 6.5$ by the saline phosphate procedure.

Effect of glycerol concentration. Glycerol-accelerated death of $20 \mu \mathrm{g} . / \mathrm{ml}$. populations occurred to similar extents at glycerol concentrations between $10 \mathrm{mM}$ and $100 \mu \mathrm{M}$ in saline phosphate $(\mathrm{pH} \mathbf{7 \cdot 3})$; the phenomenon was less pronounced at $\mathbf{5 0} \mu \mathrm{M}$ and undetectable at $10 \mu \mathrm{m}$ (contrast succinate; see below). Typical values after $\mathbf{1 ~ h r}$ of starvation were: $23 \%$ viable with $10 \mathrm{~mm}$-glycerol, $29 \%$ with $100 \mu \mathrm{M}, 41 \%$ with $50 \mu \mathrm{M}$; the control without glycerol was $82 \%$ viable, like the population with $10 \mu \mathrm{M}$ glycerol.

Effect of population density. Below a certain maximum, death by starvation is slower the denser the bacterial population (Harrison, 1960; Postgate \& Hunter, $1963 b$ ). Glycerol-accelerated death showed a comparable phenomenon (Table 2).

Table 2. Effect of population density during glycerol-accelerated death of Aerobacter aerogenes

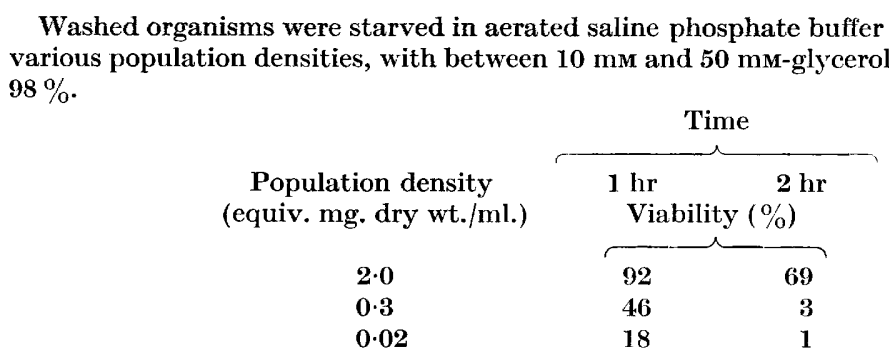

Effect of pre-treatment with glycerol. Aerobacter aerogenes organisms (250 mg./ml.) were aerated for $10 \mathrm{~min}$. at $40^{\circ}$ in saline phosphate $(\mathrm{pH} 6.5)$ with and without $30 \mathrm{~mm}$ glycerol, and then were washed, drained and tested for survival in saline phosphate ( $\mathrm{pH} \mathrm{6.5)}$ ) as usual. None died during the pre-treatment, and the death rates were similar when the organisms were subsequently starved in the plain buffer. A control suspension not pre-exposed to glycerol showed glycerol-accelerated death. Hence a brief pre-treatment of the organism with substrate did not commit them to a faster death rate than they would otherwise have shown.

Effect of metabolic intermediates. Glucose or ribose did not accelerate death (see above). Postgate \& Hunter (1962) had shown, with the saline tris procedure, that the sodium salts of pyruvate, oxaloacetate, $\alpha$-ketoglutarate, malate, succinate, or citrate accelerated death when used in place of glycerol. These compounds were retested at $10 \mathrm{~mm}$ with the saline phosphate procedure at $\mathrm{pH} 6 \cdot 3$; all accelerated death, though malate had only a small effect. Succinate appeared more effective than glycerol: like glycerol, it showed a maximum effect at $100 \mu \mathrm{M}$ or above, but gave a perceptible effect at $10 \mu \mathrm{M}$; it had no effect at $1 \mu \mathrm{M}$. Pyruvate was active over 
a concentration range similar to that of glycerol; citrate was only effective at $1 \mathrm{~mm}$ and above.

Effect of metabolic inhibitors. Postgate \& Hunter (1962) listed a variety of inhibitors tested for an effect on death of Aerobacter aerogenes starved in plain saline tris buffer. Certain of those likely to be involved in terminal oxidative metabolism were re-tested for an effect on death accelerated by $10 \mathrm{~mm}$-glycerol, with the saline tris procedure. Sodium fluoracetate $(10 \mathrm{~mm})$ or sodium fluoride ( $1 \mathrm{~mm})$ had no effect on the accelerated death rate. Sodium malonate $(2 \mathrm{~mm})$ further accelerated death with glycerol or succinate; at $400 \mu \mathrm{M}$ it had no effect. Similar results were obtained when the saline phosphate procedure was used. Sodium iodoacetate $(1 \mathrm{~mm})$ hastened glycerol-accelerated death of organisms prepared by the

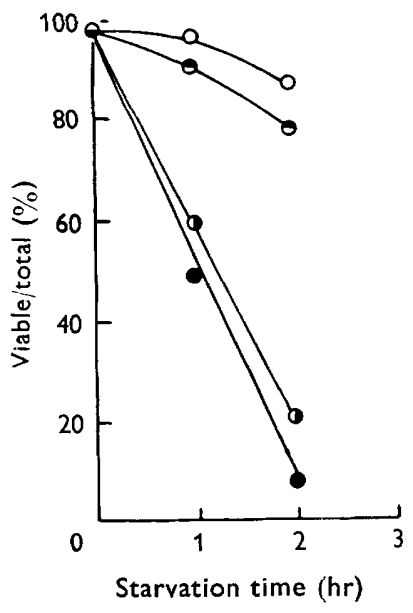

Fig. 5

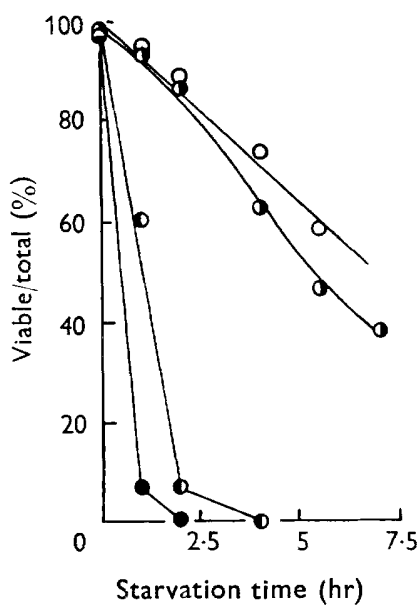

Fig. 6

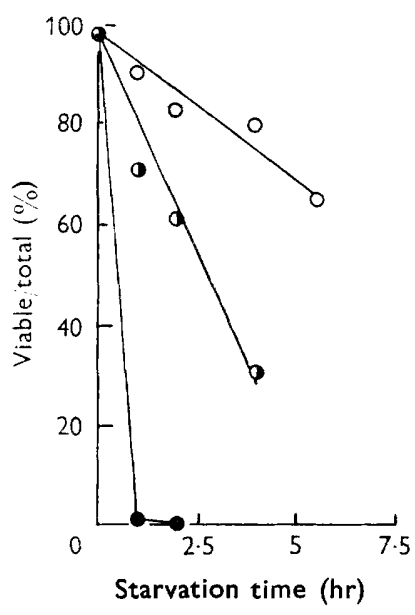

Fig. 7

Fig. 5. Demonstration of glycerol-accelerated death by plate and slide culture. Aerobacter aerogenes from a continuous culture was washed and starved at $20 \mu \mathrm{g} . / \mathrm{ml}$. in aerated saline phosphate buffer ( $\mathrm{pH} \mathrm{6.5)}$ ) at $40^{\circ}$. Viability by slide culture or by plate count after micropipette dilution (Postgate \& Hunter, $1963 \mathrm{c}$ ) in $0 \cdot 15 \mathrm{M}-\mathrm{NaCl}$; viabilities from plate counts are plotted as $\%$ initial value, taken as equal to the initial viability obtained by slide culture. $\bigcirc$, slide culture; $\ominus$, plate count on control population; $\boldsymbol{\ominus}$, slide culture; plate count on population in presence of $10 \mathrm{~mm}$-glycerol.

Fig. 6. Effect of 2,4-dinitrophenol on glycerol-accelerated death of Aerobacter aerogenes. A. aerogenes prepared as for Fig. 5 and starved in presence of: $10 \mathrm{~mm}$-glycerol; ( ) 1 mM-2,4-dinitrophenol ;, $10 \mathrm{mm-glycerol}+1 \mathrm{mm-2,4-dinitrophenol} \mathrm{;} O$, control population. Samples $(1 \mathrm{ml}$.) were centrifuged and re-suspended in $0.15 \mathrm{M}-\mathrm{NaCl}$ before estimating viability by slide culture.

Fig. 7. Glycerol utilization during glycerol-accelerated death of Aerobacter aerogenes. $A$. aerogenes prepared as for Fig. 5. $O$, viability of control population; $\bullet+1 \mathrm{~mm}$ glycerol; , proportion of glycerol remaining in centrifuged samples.

saline tris procedure, but with the saline phosphate procedure it delayed the onset of glycerol-accelerated death for up to $1 \mathrm{hr}$; death subsequently occurred at a rate similar to that of the population without inhibitor. $\alpha$-Keto- $\gamma$-valerolactone$\gamma$-carboxylic acid (KVC) inhibits $\alpha$-ketoglutarate oxidation (Montgomery \& LeydenWebb, 1954); it was tested at $10 \mathrm{~mm}$ with glycerol, $\alpha$-ketoglutarate or succinate (10 $\mathrm{mm})$ using the saline phosphate procedure and it delayed substrate-accelerated 
death with the last two compounds. With glycerol, however, no significant protection by KVC against substrate-accelerated death was observed. These observations suggested a specific protective effect by KVC, but spontaneous hydrolysis of KVC at about $\mathrm{pH} 7$ was found by observing its behaviour alone in saline tris buffer: the $\mathrm{pH}$ value dropped from $\mathrm{pH} 7$ to $\mathrm{pH} 6$ in $2 \mathrm{hr}$, and to $\mathrm{pH} 5$ in $7 \mathrm{hr}$. Little $\mathrm{pH}$ change occurred in the experiments already mentioned, but it is obvious that the agent was not stable in the test conditions. The inhibitors mentioned so far were not unequivocally protective, but two compounds showed clear positive effects with the saline phosphate procedure. Figure 6 shows protection by the uncoupling agent 2,4-dinitrophenol. Though toxic by itself at $1 \mathrm{~mm}$, this substance virtually prevented glycerol-accelerated death at that concentration. A similar effect occurred with azide: it slowed the rate of glycerol-accelerated death but did not prevent it entirely. Azide was tested between $\mathbf{1 . 5}$ and $10 \mathrm{~mm}$ and showed maximum protection at $5 \mathrm{~mm}$ : after $4 \mathrm{hr}$ at $\mathrm{pH} \mathrm{6.4,} \mathrm{when} \mathrm{the} \mathrm{populations} \mathrm{with} \mathrm{azide} \mathrm{or} \mathrm{glycerol} \mathrm{alone} \mathrm{were} \mathrm{less}$ than $3 \%$ viable, that with azide + glycerol was $26 \%$ viable; controls, with neither substance, were $55 \%$ viable. In all these experiments, azide was more toxic in plain buffer (death rate $30 \% / \mathrm{hr}$ with $1.5 \mathrm{~mm}$-azide, and $12 \% / \mathrm{hr}$ without azide, in saline phosphate buffer at $\mathrm{pH} \mathrm{6.4)}$ ) than recorded by Postgate \& Hunter (1962: $10 \% / \mathrm{hr}$ with azide, and $8 \% / \mathrm{hr}$. without azide). Azide was retested with the saline tris procedure and showed an intermediate toxic effect: $20 \% / \mathrm{hr}$ with azide, $13 \% / \mathrm{hr}$ without.

Utilization of substrate. Glycerol utilization during glycerol-accelerated death was implied by the experiments already described and by later ones (e.g. those on polysaccharide synthesis discussed below). Disappearance of glycerol during glycerol-accelerated death was followed by analysis of centrifuged samples (Fig. 7) and indicated that glycerol utilization continued after all the population was empirically 'dead'. The respiratory quotient of starved organisms declines in parallel with the viability during starvation (Postgate \& Hunter, 1962) and the effect of presence of substrate during conventional Warburg respirometry was therefore examined. In a typical experiment, eight Warburg vessels were set up with conventional quantities of organism and glycerol; two without glycerol served as blanks. At intervals, pairs of vessels were removed for viability determination by slide culture. Figure 8 illustrates the most impressive of these experiments; in others glycerol-accelerated death was less pronounced during the $80-\mathrm{min}$. period but was nevertheless clear. Its extent presumably depended on whether the organisms utilized all the substrate before it 'killed' them.

Effect of magnesium. Magnesium delays death from starvation in saline tris buffer or saline phosphate buffer (Postgate \& Hunter, 1962). At 1.25 mm (its concentration in the growth medium) $\mathbf{M g}$ abolished glycerol-accelerated death in both buffers (Fig. 9). Other major components of the growth medium $\left(\mathrm{K}_{2} \mathrm{SO}_{4}, 10 \mathrm{~mm}\right.$; $\left.\left(\mathrm{NH}_{4}\right)_{2} \mathrm{HPO}_{4}, 4.5 \mathrm{~mm}\right)$ as a mixture had no effect. Experiments were made to determine the minimum effective magnesium concentration: in saline phosphate (pH 6.3), $\mathrm{MgCl}_{2}$ between 6.25 and $12.5 \mu \mathrm{M}$ brought the death rate of a $20 \mu \mathrm{g} . / \mathrm{ml}$. suspension with $10 \mathrm{~mm}$ glycerol back to that of a comparable suspension without glycerol and magnesium; $25 \mu \mathrm{M}-\mathrm{MgCl}_{2}$ lowered the death rate to that with magnesium but no substrate. $\mathrm{FeCl}_{3}(1.6 \mathrm{~mm})$ or $\mathrm{CaCl}_{2}(0 \cdot 1 \mathrm{~mm})$, which had some protective action on organisms starved in plain buffer, did not influence glycerol-accelerated 
death at $\mathrm{pH} 6.4$ in saline phosphate buffer. $\mathrm{MnCl}_{2}(25 \mu \mathrm{M})$, which had no effect on organisms starved in plain buffer, antagonized glycerol-accelerated death to a slight extent. For example, all of an initially $99 \%$ viable population were dead after $1 \mathrm{hr}$ in saline phosphate buffer $+10 \mathrm{~mm}$ glycerol ( $\mathrm{pH} \mathrm{6} \cdot 4)$, whereas in a similar solution with $\mathrm{MnCl}_{2}$ they were $27 \%$ viable. The control suspension was $96 \%$ viable.

Polymer catabolism. Death of Aerobacter aerogenes by starvation is preceded by the metabolism of certain polymeric cell constituents (Strange et al. 1961). Polymer catabolism with and without glycerol was studied, using the saline phosphate procedure and the assay methods cited by Postgate \& Hunter (1962). No significant change in the DNA and protein contents of 240 and $300 \mu \mathrm{g} . / \mathrm{ml}$. suspensions,

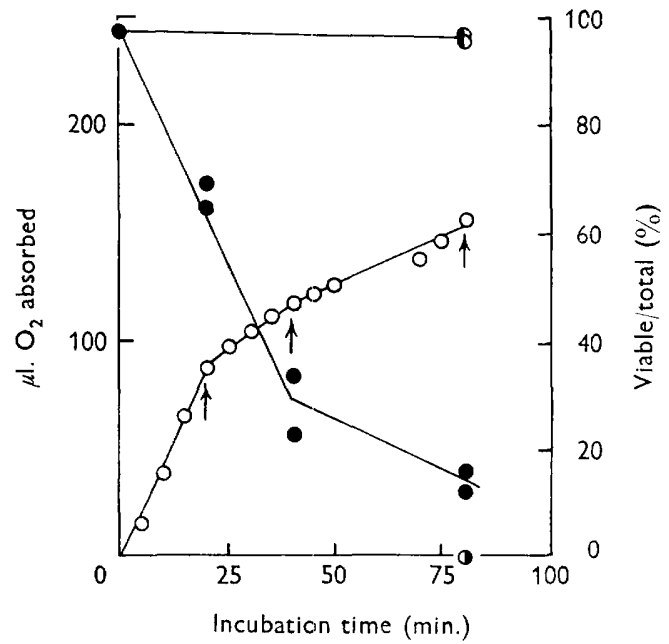

Fig. 8

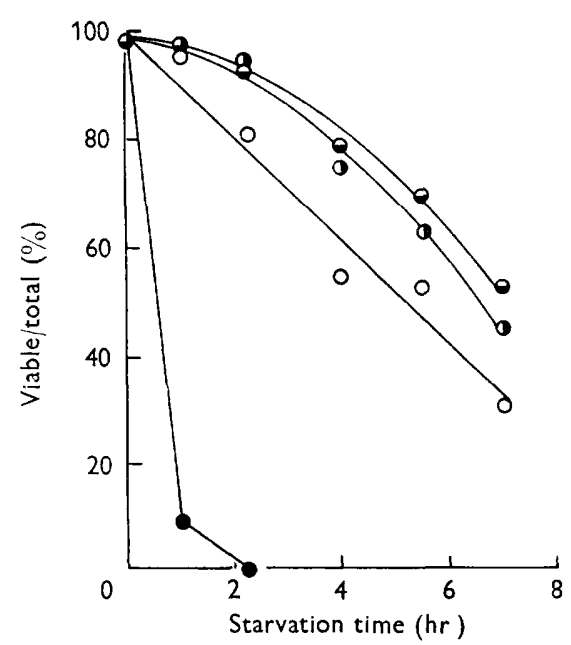

Fig. 9

Fig. 8. Substrate-accelerated death during Warburg respirometry. Warburg vessels containing equiv. $2 \mathrm{mg}$. dry wt. organism in $2 \mathrm{ml}$. saline phosphate buffer (pH 7.3); $0 \cdot 1 \mathrm{ml}$. KOH $(10 \mathrm{M})$ in centre well; vessels were equilibrated at $40^{\circ}$ and, after tipping $3 \cdot 26 \mu$ mole glycerol in $0.2 \mathrm{ml}$. water as substrate, pairs of vessels were dismantled during the reaction (times indicated by arrows) for viability determination on their contents by slide culture after dilution in $0 \cdot 15 \mathrm{M}-\mathrm{NaCl}$. $\mathrm{O}$, mean $\mathrm{O}_{2}$ uptake values for pairs of vessels with glycerol; 1 , blank pair without glycerol; $\mathbf{O}$, viabilities of populations in individual flasks with glycerol; $D$, viabilities of blank pair.

Fig. 9. Abolition of glycerol-accelerated death of Aerobacter aerogenes by magnesium ions. $A$. aerogenes prepared as for Fig. 5 and starved in saline phosphate buffer (pH 6.3). Viabilities by slide culture. $O$, control population; $\odot,+10 \mathrm{~mm}$-glycerol; $\ominus,+1 \cdot 25 \mathrm{~mm}-\mathrm{MgCl}_{2}$; - + glycerol $+\mathrm{MgCl}_{2}$.

respectively, occurred at $\mathrm{pH} 7 \cdot 3$ over $2 \mathrm{hr}$, although the viabilities fell to 2 and $4 \%$ with $10 \mathrm{~mm}$ glycerol. Without glycerol, the viabilities were unchanged at $\mathbf{9 6 - 9 8} \%$. In three experiments the polysaccharide contents of $750 \mu \mathrm{g} . / \mathrm{ml}$. suspensions (pH 7.3) increased 2.1- to 3-fold in 2-4 hr, while the viabilities fell from $99 \%$ to between 60 and $80 \%$ and the control populations without glycerol remained wholly viable. RNA catabolism, indicated by the Bial reaction, was slower with $100 \mu \mathrm{g} . / \mathrm{ml}$. populations at $7 \cdot 3$ and $\mathrm{pH} 6 \cdot 4$ than recorded by Postgate $\&$ Hunter (1962). This may be related to the longer survival of populations treated by the saline phosphate procedure compared with those prepared by the saline tris procedure. At neither 
$\mathrm{pH}$ value was the rate of RNA breakdown altered when death was accelerated with $25 \mathrm{~mm}$ glycerol, though after $4 \mathrm{hr}$ these populations were $85 \%$ to $98 \%$ dead and the viabilities of control populations without glycerol had scarcely changed from the starting value of $97 \%$. Both showed a 10-15\% decrease in RNA content over this period.

Excretion of materials. Micro-organisms starved in buffer excrete into the medium materials which absorb radiation at about $260 \mathrm{~m} \mu$ (see Strange et al. 1961; Postgate \& Hunter, 1962). Differences in the amounts of such materials were not detected during the death of a $60 \mu \mathrm{g} . / \mathrm{ml}$. population dying in saline phosphate buffer, with or without $30 \mathrm{~mm}$-glycerol, because a strong absorption at about $230-240 \mathrm{~m} \mu$ appeared which obscured the $260 \mathrm{~m} \mu$ peak. This absorption reached an apparent maximum in $2 \mathrm{hr}$, during which time the viability of the population decreased from 99 to $2 \%$; the control population decreased from 98 to $86 \%$ viable. Twenty-fold concentrates of saline phosphate buffer ( $\mathrm{pH} 6 \cdot 4$ ) in which $20 \mu \mathrm{g} . / \mathrm{ml}$. populations had died during incubation for $7 \mathrm{hr}$, with or without $10 \mathrm{~mm}$-glycerol, had different appearances. Those from the populations whose death had been accelerated by glycerol were brownish-yellow in colour and had a pronounced white fluorescence in light of $365 \mathrm{~m} \mu$ wavelength; the controls were colourless and showed little fluorescence. The cyanide reaction (Ciotti \& Kaplan, 1957) indicated that, after glycerol-accelerated death, pyridine nucleotides (equivalent to about $5 \mu \mathrm{M}$ in the original buffer) were present which were absent from the controls. Since loss of these materials may have been a factor in glycerol-accelerated death, mixtures of nicotinamide adenine dinucleotide and nicotinamide adenine dinucleotide phosphate (10 and $33 \mu \mathrm{M}$ ) were tested with the saline phosphate procedure. These compounds did not influence glycerol-accelerated death. Attempts were made to measure the magnesium contents of such concentrates. Analyses of whole bacteria prepared as for the saline phosphate procedure indicated $0 \cdot 19 \%(\mathrm{w} / \mathrm{w}) \mathrm{Mg}$; hence our conventional $20 \mu \mathrm{g} . / \mathrm{ml}$. suspensions corresponded to $1.6 \mu \mathrm{M}$ magnesium. In our hands the Titan Yellow procedure would just have detected the $\mathbf{M g}$ in $\mathbf{2 0}$-fold concentrates of such a solution, but analyses of concentrates of buffers after bacterial death with or without glycerol showed no detectable magnesium. $\mathbf{M g C l}_{\mathbf{2}}$ added to such concentrates was recovered quantitatively; hence other materials in the concentrates did not interfere with the analysis. Concentrated buffers in which denser $(200 \mu \mathrm{g} . / \mathrm{ml}$.) populations had died did interfere, however; they delayed the appearance of the red colour and lowered the blank reading, as well as diminishing the recovery of added $\mathrm{MgCl}_{2}$. Buffers from populations subjected to glycerol-accelerated death for $6.5 \mathrm{hr}$ interfered to a lesser extent than controls from populations without glycerol. Evaporation of such concentrates with $\mathrm{H}_{2} \mathrm{SO}_{4}$ followed by $\mathrm{NaOH}$, to remove the volatile acids and $\mathrm{NH}_{3}$ which interfere with the Titan Yellow reaction (Feigl, 1954), did not prevent this interference. Both types of concentrate interfered with the 'magneson' reaction (Anon. 1949).

State of the osmotic barrier. Postgate \& Hunter (1962) used the optical effect of Mager, Kuczynski, Schatsberg \& Avi-dor (1956), and permeability to a dyestuff that fluoresced in contact with protein, to show that the osmotic barriers of Aerobacter aerogenes organisms starved by the saline tris procedure remained functional after death. Comparable experiments with the saline phosphate procedure showed that glycerol-accelerated death at $\mathrm{pH} 7 \cdot 3$ did not involve accelerated breakdown of the 
osmotic barrier. Some experiments with the saline tris procedure, and measurement of the permeability to anilino-naphthalene sulphonic acid fluorimetrically, confirmed that glycerol- or succinate-accelerated death did not involve accelerated breakdown of the osmotic barrier in these conditions.

State of the 'permeability control mechanism'. 'Cold shock' is characterized by release of undegraded ATP and amino acids into the environment and has been interpreted in terms of inhibition of a permeability control mechanism by abrupt chilling (Meynell, 1958; Strange \& Dark, 1962). Since cold shock only occurs among organisms from exponentially growing cultures, it was conceivable that exposure of starving organisms to their limiting substrate might induce a state physiologically analogous to susceptibility to cold shock. Leakage of products comparable to those which appear during cold shock, as well as susceptibility to cold shock, were therefore sought during glycerol-accelerated death. Suspensions of Aerobacter aerogenes (2 mg. $/ \mathrm{ml}$.) dying at $\mathrm{pH} 6.5$ in saline phosphate, with and without $50 \mathrm{~mm}$-glycerol, were sampled after 1 and $2 \mathrm{hr}$ (glycerol-accelerated populations fell to $66 \%$ viable; controls unchanged at $\mathbf{9 7} \%$ ), filtered rapidly into an ice-cold receiver through a membrane filter (Oxoid), the filtrates frozen in liquid nitrogen and stored at $\mathbf{- 2 0 ^ { \circ }}$ for examination next day. ATP was sought by the firefly luminescence technique; none was detected. Cold shock would have released readily detectable amounts of ATP from a susceptible population of this density (Strange \& Dark, 1962). Chromatographic examination of the filtrates indicated no enhancement of the amino acid excretion in the presence of glycerol. Our populations of $A$. aerogenes do not ordinarily show cold shock (Postgate \& Hunter, 1961). No signs of susceptibility to cold shock (increased death after chilling for 30 min. at $4^{\circ}$ ) appeared during the death of an $80 \mu \mathrm{g}$. $/ \mathrm{ml}$." suspension accelerated by $40 \mathrm{~mm}$-glycerol in saline phosphate ( $\mathrm{pH} 7 \cdot 3$ ), nor during starvation of a control population without glycerol. The test population decreased from 98 to $17 \%$ viable during the $60 \mathrm{~min}$. starvation period; the control did not die at all. Strange \& Dark (1962) showed that certain concentrations of spermine had a slight protective effect against cold shock. Spermine at $10 \mu \mathrm{M}$ did not influence glycerol-accelerated death of a $20 \mu \mathrm{g} . / \mathrm{ml}$. population at pH 6.3 in saline phosphate buffer; at $100 \mu \mathrm{M}$ spermine accelerated death.

\section{DISCUSSION}

Ubiquity of substrate-accelerated death. Substrate-accelerated death appears to be a fairly general phenomenon associated with the survival of starved Aerobacter aerogenes. It can be observed in organisms harvested from complex media, in which the 'limiting' nutrient is not known and may change as the culture grows. It occurs with other Gram-negative bacteria. Substrate-accelerated death differs in principle from the 'suicidal' behaviour of certain mutants (e.g. inositol-less Neurospora crassa, Strauss, 1958; thymine-less Escherichia coli, Barner \& Cohen, 1956), because 'suicidal' behaviour is provoked by withdrawal of the required nutrient in conditions otherwise favourable to growth, whereas our phenomenon is elicited by providing a previously needed substrate in conditions which, nevertheless, remain unfavourable for growth. Substrate-accelerated death of $A$. aerogenes occurred whether the limiting substrate was the nitrogen, phosphorus or carbon-cum-energy source; it was not observed when the sulphur source limited growth, though in this instance 
the carbon source continued to accelerate death. It seems possible that the sulphur source limited growth indirectly by influencing the rate of some step in carbon utilization. Magnesium-limited organisms did not show substrate-accelerated death, but this is reasonable since $\mathbf{M g}$ ions protect ordinary starved populations, irrespective of nutritional status (Postgate \& Hunter, 1962). Magnesium prevented substrateaccelerated death brought about by glycerol.

The fact that the nutritional status of the population determines which substrate, if any, will accelerate death presumably explains certain conflicting reports in the literature cited by Postgate \& Hunter (1963a), who pointed out the relevance of substrate-accelerated death to the design of physiological experiments which make use of live 'resting' bacteria; e.g. enzyme induction, respirometry and the replacement of 'maintenance energy' by small additions of substrate. Figure 8 illustrates an extreme case of substrate-accelerated death during Warburg respirometry, and though the existence of such a phenomenon need not necessarily invalidate the conclusions obtained from the respirometric experiments, it seems likely from our data that part of the 'uncoupling' effect of compounds such as azide and 2,4dinitrophenol in respirometry might be connected with the preservation of viability.

Action of magnesium. The antagonism of glycerol-accelerated death by magnesium showed some differences from the protection these ions ordinarily afford against starvation. Calcium ions had no action in place of $\mathbf{M g}$ ions and $\mathrm{Fe}^{3+}$ ions were not protective. Manganese ions, which had no protective effect in ordinary starvation (this observation was re-checked with the saline phosphate procedure), may have antagonized glycerol-accelerated death by sparing the organisms' reserves of magnesium ions. Strange \& Shon (1964) showed that organisms washed in $\mathrm{NaCl}$ solutions lost more magnesium than those washed in distilled water and became more sensitive to a mild heat stress. A comparable retention of stored magnesium might account for the lower sensitivity to glycerol-accelerated death of organisms washed in distilled water compared with those washed in saline.

Mechanism of substrate-accelerated death. The data presented here do not allow a complete account of substrate-accelerated death and do not establish whether the inorganic substrates, ammonium or phosphate, accelerate the death of susceptible populations by a mechanism similar to that of carbon-cum-energy sources such as glycerol, glucose or lactate. For the case of glycerol-accelerated death, the excretion of coloured and fluorescent material, together with the existence of a population effect, implicate a loss, from dying organisms, of materials which, once they reach a threshold concentration, prolong the lives of the surviving neighbours (seediscussion of population effects by Harrison, 1960, and Postgate \& Hunter, 1963b). Magnesium ions may be among the relevant materials excreted, but if so their concentration was below the range of analytical procedures available to us. The release of such materials must be precipitated by the presence of glycerol or some active substitute for it; their release required the continued presence of glycerol in the starvation environment but not in the medium used to assess viability; it did not involve accelerated breakdown of the osmotic barrier, nor did changed permeability characters appear that resembled those which render logarithmic-phase organisms susceptible to cold shock. Accelerated breakdown of the endocellular polymers, DNA, RNA and protein, did not occur and polysaccharide was laid down during glycerol-accelerated death. 
The long lags shown by survivors of substrate-accelerated death, which occurred with inorganic and with organic substrates, suggests that reclamation of the lost material after transfer to the recovery medium was a slow process, or that the active substrate influenced the organisms' metabolism in such a way that their behaviour then resembled that of bacteria subject to repression of enzyme synthesis. Recovery from repression is known to involve long lags (Bourgeois, Wiame \& Lelouchier-Dagnelie, 1960) and several instances are known in which a substrate may repress synthesis of its own enzyme. For example, $\beta$-galactosidase synthesis by partly adapted Escherichia coli may be repressed by lactose (Mandelstam, 1961) and in this instance not only are intermediates in the metabolism of lactose also repressive but repression is antagonized by 2,4-dinitrophenol. Hypotheses based on analogy with the repression of enzyme synthesis would be consistent with the fact that glycerol continues to be utilized by operationally 'dead' organisms (Fig. 7), despite the finding of Postgate \& Hunter (1962) that metabolism of glycerol declined in parallel with viability during death in a plain buffer, because such hypotheses would envisage repression during turnover of some factor essential for subsequent multiplication. The existing complement of catabolic enzymes would be primarily unaffected by the active substrate. However, the chemical disparity of the agents that induce substrate-accelerated death, together with the variety of intermediates that can replace glycerol, and the capriciousness with which utilizable substrates which are not intermediate metabolites may or may not accelerate death, all make it clear that simple repression of an enzyme sequence involved in the utilization of the substrate provides an inadequate theoretical approach. The active substrate must trigger-off some more central process in the regulatory mechanism of the organism, presumably one concerned with the issue or transfer of genetic information for constitutive biosynthetic reactions.

We are indebted to Miss Patricia Mills for technical assistance, and acknowledge gratefully the help of Messrs F. A. Dark, A. G. Ness, R. E. Strange, H. K. Robinson and H. E. Wade, who performed various analyses for us. Dr S. L. S. Thomas of the National Chemical Laboratory kindly gave the specimen of KVC.

\section{REFERENCES}

Anon. (1949). The B.D.H. Book of Organic Reagents. Poole: The British Drug Houses Ltd. Barner, H. D. \& Cohen, S. C. (1956). The relation of growth to the lethal damage induced by ultra-violet irradiation in Escherichia coli. J. Bact. 71, 149.

Bourgeois, S., Wiame, J. M. \& Lelouchier-Dagnelie, H. (1960). Étude du 'rétrocontrole' de synthèses d'enzymes par des acides aminés au cours de la croissance de Proteus morganii. Biochim. biophys. Acta, 38, 136.

Ciotri, M. M. \& Kaplan, N. O. (1957). Procedures for determination of pyridine nucleotides. In Methods in Enzymology. Ed. by S. P. Colowick \& N. O. Kaplan. Vol. 3, p. 890. New York: Academic Press.

Feigl, F. (1954). Spot Tests. Vol. 1. London: Elsevier.

GARNER, R. J. (1946). Colorimetric determination of magnesium in plasma or serum by means of Titan Yellow. Biochem. J. 40, 828.

Harrison, A. P., JUn. (1960). The response of Bacterium lactis aerogenes when held at growth temperature in the absence of nutriment: an analysis of survival curves. Proc. Roy. Soc. B, 152, 418. 
Mager, J., Kuczynski, M., Schatzberg, G. \& Avi-Dor, Y. (1956). Turbidity changes in bacterial suspensions in relation to osmotic pressure. J. gen. Microbiol. 14, 69.

MANDElstaM, J. (1961). Induction and repression of $\beta$-galactosidase in non-growing Escherichia coli. Biochem. J. 79, 489.

Medical Research Council (1931). A System of Bacteriology in Relation to Medicine. London: H.M.S.O.

Meynell, G. G. (1958). The effect of sudden chilling on Escherichia coli. J. gen. Microbiol. $19,380$.

Montgomery, C. M. \& Leyden-Webs, J. (1954). Detection of a new inhibitor of the tricarboxylic acid cycle. Science, $120,843$.

NeIsi, A. C. (1950). Analytical Methods for Bacterial Fermentations. Nat. Res. Council, Canada, Rep. 46-8-3, Saskatoon.

Postgate, J. R. \& Hunter, J. R. (1961). On the survival of frozen bacteria. J. gen. Microbiol. 26, 367.

Postgate, J. R. \& Hunter, J. R. (1962). The survival of starved bacteria. J. gen. Microbiol. 29, 233.

Postgate, J. R. \& Hunter, J. R. (1963a). Acceleration of bacterial death by growth substrates. Nature, Lond. 198, 273.

Postgate, J. R. \& Hunter, J. R. (1963b). The survival of starved bacteria. J. appl. Bact. 26, 295.

Postgate, J. R. \& Hunter, J. R. (1963c). Metabolic injury in frozen bacteria. J. appl. Bact. 26, 405.

Postgate, J. R., Crumpton, J. E. \& Hunter, J. R. (1961). The measurement of bacterial viabilities by slide culture. J. gen. Microbiol. 24, 15.

Strange, R. E. \& Dark, F. A. (1962). Effect of chilling on Aerobacter aerogenes in aqueous suspension. J. gen. Microbiol. 29, 719.

Strange, R. E. \& Shon, M. (1964). Effects of thermal stress on viability and ribonucleic acid of Aerobacter aerogenes in aqueous suspension. J. gen. Microbiol. 34, 99.

Strange, R. E., Dark, F. A. \& Ness, A. G. (1961). The survival of stationary phase cells of Aerobacter aerogenes stored in aqueous suspension. J. gen. Microbiol. 25, 61.

Strauss, B. S. (1958). Cell death and 'unbalanced growth' in Neurospora. J. gen. Microbiol. 18, 658.

\section{ADDENDUM}

An earlier paper by Postgate \& Hunter (1962) contained several errors. We publish the following table of corrections and apologize to anyone who may have been misled.

\section{Reference}

Page 236, line 13

Page 237, line 22

Page 240, sketch

Page 245, last line

Page 246, table 2

Page 246, table 2

Page 248, line 36

Page 253, table 4)

Page 254, line 10$\}$

Page 255, Fig. 12

Page 256, Fig. $13 a$

Figs. 2-5, 11, 13-16

\section{Correction}

For $\pm 0 \cdot 01 / \mathrm{hr}^{-1} \mathrm{read} \pm 0.01 \mathrm{hr}^{-1}$

For Millipore read membrane

For 26.7 read $96 \cdot 7$

For $\times 10^{+5} \mathrm{M}$ read $\times 10^{-5} \mathrm{M}$

Insert no after or in last column

For Fig. 9 read Fig. 7 (in note marked $\dagger$ )

For uracil read uridine

For $0.31 \mathrm{~mm}-\mathrm{Na}_{2} \mathrm{SO}_{4}$ read $0.031 \mathrm{~mm}-\mathrm{Na}_{2} \mathrm{SO}_{4}$

Label ordinate viable/total, $\%$

Third point in $D=0 \cdot 44$ curve should have symbol

For \% viable total read viable/total, \% 